\title{
Crescimento vegetativo e produtividade do cafeeiro irrigado no sul do Estado de Minas Gerais ${ }^{1}$
}

\author{
Natalino M. Gomes², Luiz A. Lima ${ }^{3} \&$ Anselmo A. de P. Custódio ${ }^{4}$
}

\begin{abstract}
RESUMO
O conhecimento e o manejo dos principais fatores relacionados à produção, dentre os quais a irrigação é de fundamental importância, razão por que se objetivou, com este trabalho, avaliar o efeito de diversas lâminas de irrigação no crescimento vegetativo, desenvolvimento e produtividade de cafeeiros, desde a fase inicial de formação até a quinta safra. As lâminas de água aplicadas em função da evaporação do tanque Classe "A" (ECA), foram: 60\% (T2); 80\% (T3); 100\% (T4); 120\% (T5); e 140\% (T6) da ECA, além de tratamento testemunha não irrigado (T1). Avaliaram-se, a cada mudança de estação, variáveis vegetativas e, após as colheitas, a produtividade das parcelas experimentais para as safras 00/01, 01/02, 02/03, 03/04 e 04/05; mesmo não havendo diferença estatística significativa na comparação de safras anuais para as irrigações se nota, ao se comparar a produção total acumulada das safras, diferença estatística entre a testemunha e os tratamentos irrigados, destacando-se a lâmina de $60 \%$ da ECA, com a qual a produção total acumulada foi de 225,6 sc e a média anual de $45,12 \mathrm{sc} \mathrm{ha}^{-1}$, acréscimo de $119 \%$ na produtividade do cafeeiro comparado-a ao tratamento não irrigado, que produziu, em média, 22,5 sc ha-1 ano-1.
\end{abstract}

Palavras-chave: irrigação, café, pivô central, tanque classe A

\section{Vegetative growth and yield of irrigated coffee in southern region of State of Minas Gerais - Brazil}

\begin{abstract}
The knowledge and management of the principal factors related to production and irrigation is highly important. Irrigation effects on vegetative growth and yield of coffee were evaluated, from initial growth up to five years of production. The experimental design was randomized blocks with 6 treatments and three replications. The water depths applied were based on Class A evaporation pan (ECA), as 60\% (T2); 80\% (T3); 100\% (T4); 120\% (T5); and 140\% (T6) of ECA, as well as a non irrigated control (T1). The following parameters were evaluated in each season: vegetative variable and the yields obtained during the years 2000/2001, 2001/2002, 2002/2003, 2003/2004 and 2004/2005. Although no statistical differences could be observed in yearly harvests after comparing the total production obtained in each treatment, significant differences were obtained when non irrigated to irrigated plots were compared, especially for the $60 \% \mathrm{ECA}$. At this level, the total production was 225.6 bags and the average was 45.12 bags ha-1, $119 \%$ larger than the non irrigated plots,

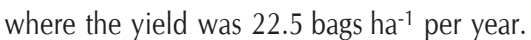

Key words: irrigation, coffee, center pivot, class A evaporation pan

\footnotetext{
1 Trabalho financiado pelo PNP\&D/CAFÉ - EMBRAPA (19.2002.317-05)

2 Professor EAFAJT - CP 09, CEP 46.430-000, Guanambi, BA, Distrito de Ceraíma, Zona Rural. Fone: (77) 3459-2100. E-mail: natalagricola@yahoo.com.br.

3 Professor DEG/UFLA. Fone: (35) 3829-1389. E-mail: lalima@ufla.br

${ }^{4}$ Mestrando em Engenharia de Água e Solo/UFLA, C.P. 3037, CEP 37200000, Lavras, MG. Fone: (35) 3829-1389. E-mail: b1uflagro@yahoo.com.br
} 


\section{INTRODUÇÃO}

Segundo Camargo (1987), considera-se que o café arábica apresenta quatro fases fenológicas distintas no decorrer do ano: granação e abotoação, dormência, floração e expansão (chumbinho); ele relata também que nas condições da região Centro-sul o déficit hídrico na fase de chumbinho (outubro a dezembro) atrasa o crescimento dos frutos, resultando em seu baixo diâmetro (não desejado para a comercialização), e redução da produtividade. Matiello et al. (1995) observaram, no Sul de Minas Gerais e no Estado do Rio de Janeiro, no período de 1994 a 1995, em café arábica e Conillon, o abortamento dos botões florais antes de sua abertura, após chuvas insuficientes de 3 a $8 \mathrm{~mm}$, que provocam o crescimento inicial dos botões, que não chegam a abrir e secam.

Na fase de maturação e abotoação (abril a junho), o déficit hídrico não afeta a maturação dos frutos já formados nem a produtividade do ano porém, prejudica a abotoação e a frutificação do ano seguinte; já na fase de dormência (julho a setembro), a deficiência hídrica pode ser até benéfica pelo fato de condicionar um florescimento abundante após chuvas ou regas, no final da fase, resultando em frutificação e maturação igualada na safra seguinte (Camargo, 1987).

Scalco et al. (2002) observaram que sem o uso da irrigação o crescimento das plantas foi reduzido em todas as avaliações realizadas durante o ano, e houve tendência de redução no crescimento das plantas, nas avaliações de agosto e novembro, visto que o turno de rega aumentou em função dos maiores valores de tensão de água no solo, mesmo tendo havido precipitações antes da última avaliação.

Sorice (1999) relata que a irrigação por gotejamento propiciou aumento na produtividade, da ordem de 95 a 120\%, quando comparada com a testemunha, obtendo produtividade de 24,6 Sc ha-1. Em trabalho realizado por Faria et al. (2001), na região de Lavras, MG, na safra de 1999/2000 com a cultivar Acaia Cerrado (MG-1474), densidade populacional de 5.555 plantas ha-1, plantadas no espaçamento de 3,0 m x 0,6 m irrigando-se durante todo o ano, testando cinco diferentes lâminas de irrigação e três parcelamentos de adubação de $\mathrm{N}$ e K (3, 6 e 9), as lâminas $\mathrm{L}_{1}$ (100\% ECA), $\mathrm{L}_{2}$ (80\% ECA), $\mathrm{L}_{3}$ (60\% ECA) e $\mathrm{L}_{4}$ (40\% ECA), proporcionaram incrementos de produção de 148,61; 136,55; 109,69 e $77,38 \%$, respectivamente, a mais que a testemunha $\mathrm{L}_{0}(0 \%$ ECA) e as parcelas que receberam 3 parcelamentos de adubação apresentaram os melhores resultados.

Antunes et al. (2000) irrigaram e fertirrigaram, durante o ano, uma lavoura da variedade Catuaí, com oito anos de idade, espaçamento de 1,0 m x 2,5 m, na região do Campo das Vertentes, no município de Rio Preto, MG. Ao final dos anos agrícolas de 98/99 e 99/00, obtiveram as seguintes produtividades: 43,37 e 78,1 sc ha-1 ${ }^{-1}$ respectivamente.

Tendo em vista a racionalização da exploração agrícola a caminho da sustentabilidade e a incorporação de novas tecnologias pela cafeicultura, tornam-se necessários o domínio, o conhecimento e o manejo dos principais fatores relacionados à produção, dentre os quais a irrigação é de fundamental importância. Neste contexto se objetivou, através do tra- balho, estudar o efeito de diversos níveis de lâmina de água e seu reflexo no desenvolvimento vegetativo e produtivo de cafeeiros, desde a fase de formação até a quinta safra.

\section{MATERIAL E MÉTODOS}

O ensaio foi conduzido em área experimental do Departamento de Engenharia da Universidade Federal de Lavras - UFLA, MG, na latitude de $21^{\circ} 14^{\prime} \mathrm{S}$, longitude de $45^{\circ} 00^{\prime} \mathrm{W}$ e altitude de $910 \mathrm{~m}$. A cultivar utilizada foi a Rubi, plantada em março de 1999, no espaçamento de 3,5 m entre linhas e $0,8 \mathrm{~m}$ entre plantas, em nível, com densidade de plantas de 3.571 plantas ha-1 ${ }^{-1}$ O solo da área foi classificado como Latossolo Vermelho escuro, apresentando as seguintes características químicas: pH em água, 4,6; matéria orgânica, 1,9 dag kg-1; P disponível (Mehlich-1), 5,2 $\mathrm{mg} \mathrm{dm}^{-3}$; potássio, magnésio, alumínio tocáveis de 0,$3 ; 0,9$ e $0,4 \mathrm{cmol}_{\mathrm{c}} \mathrm{dm}^{-3}$, respectivamente; $\mathrm{H}+\mathrm{AL}$, $6,3 \mathrm{cmol}_{\mathrm{C}} \mathrm{dm}^{-3}$; CTC a pH 7,0 de $8,6 \mathrm{cmol}_{\mathrm{c}} \mathrm{dm}^{-3}$ e saturação de base de $26,3 \%$. A composição textural do solo na área experimental é muito argilosa, com 22\% de areia, $2 \%$ de silte e $76 \%$ de argila.

O delineamento experimental adotado foi de blocos casualizados com 6 tratamentos e 3 repetições. Os tratamentos corresponderam às lâminas de água aplicadas em função da evaporação do tanque Classe “A” (ECA), assim descritos: 60\% (T2), 80\% (T3), 100\% (T4), 120\% (T5) е 140\% (T6), além de tratamento testemunha (T1), no qual não se fizeram irrigações.

As irrigações foram feitas por meio de um pivô central equipado com emissores tipo difusor (spray), distanciados aproximadamente 2,20 m entre si e 2,0 m das copas das plantas. Fez-se, diariamente, monitoramento da evaporação do tanque classe "A” (ECA), base para os cálculos das lâminas a serem aplicadas junto à Estação Climatológica da UFLA, situada nas proximidades do experimento. Adotou-se turno de rega fixo de 2 e 3 dias para a realização das irrigações e nos dias em que ocorreram precipitações, balanços foram realizados entre o total precipitado e a evaporação no período, para realização ou não das irrigações.

As diferentes lâminas de água correspondentes aos tratamentos foram controladas mediante o ajuste da velocidade do pivô (regulagem do percentímetro). No tratamento testemunha o pivô central se deslocava sobre as parcelas, sem aplicar água. Os tratos culturais foram feitos de maneira convencional, cujas adubações se comportavam de acordo com Santinato et al. (1996).

A área irrigada pelo pivô central, 1,6 ha, foi dividida em 18 áreas menores (segmentos de $20^{\circ}$ ), que constituíram as parcelas experimentais, apresentando formato semelhante a "fatias de pizza"; dentro dessas parcelas foram amostradas oito plantas, para avaliação das variáveis vegetativas (altura de planta, diâmetro de caule e copa, número de ramos plagiotrópicos, comprimento de ramos plagiotrópicos e número de internódios de ramos plagiotrópicos no terço médio da planta) a cada mudança de estação (março, junho, setembro e dezembro), no período 
de set/1999 a dez/2004. Após as colheitas avaliou-se a produtividade das parcelas experimentais, café de pano, em sacas de $60 \mathrm{~kg} \mathrm{ha}^{-1}$, para as cinco safras referentes aos anos agrícolas de 2000/2001 a 2004/2005.

\section{RESULTADOS E DISCUSSÃO}

\section{Precipitações e lâminas aplicadas}

A Figura 1 mostra os valores de precipitação (P) e evaporação do tanque classe (ECA) para Lavras, no período em que o experimento foi realizado (1999 a 2005), indicando haver concentração das precipitações para a região de Lavras, entre os meses de novembro a março, em que os valo-

A.

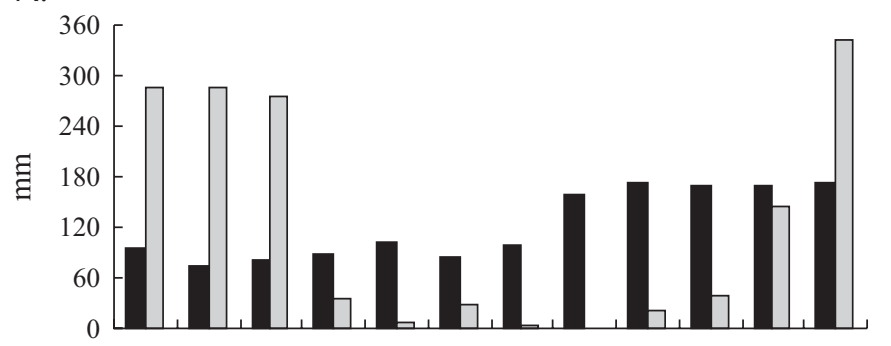

C.

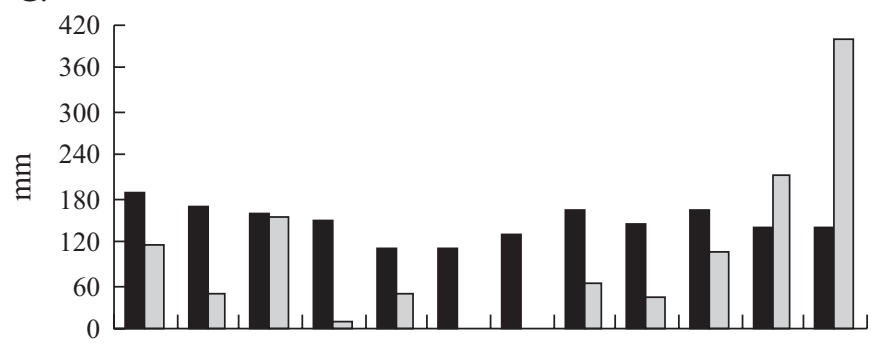

E.

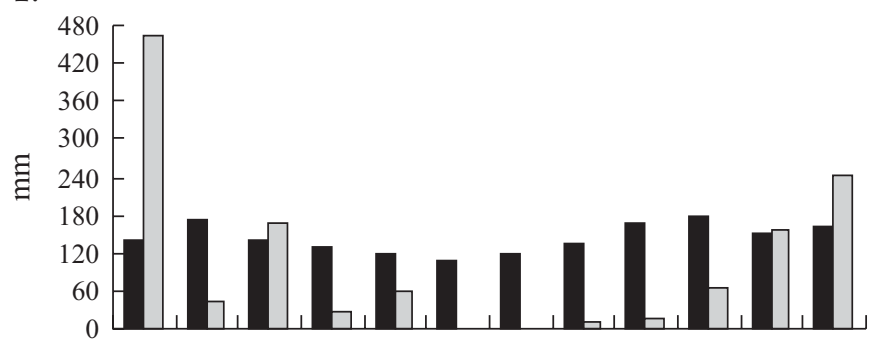

G.

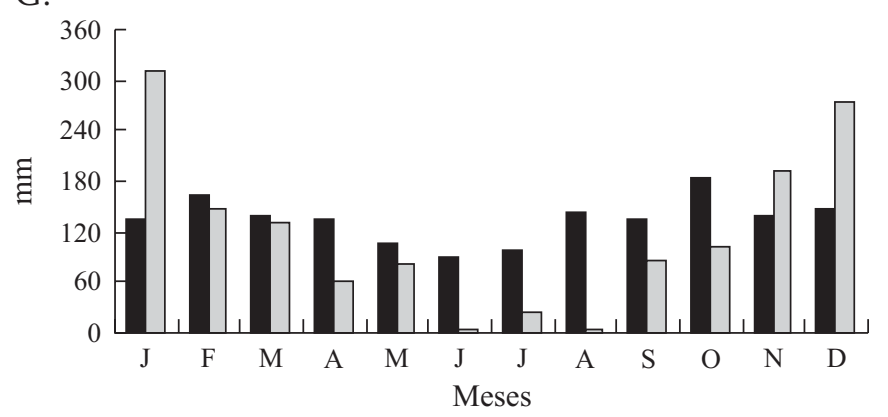

ECA $\square \mathrm{P}$ res precipitados superam consideravelmente a ECA enquanto nos meses de abril a outubro a precipitação é bem inferior à ECA, caracterizando-se déficit hídrico no período; essas informações estão de acordo com Castro Neto (1986), ao relatarem que a estação chuvosa para Lavras se estende de outubro a março e a seca compreende os meses de abril a setembro.

O balanço entre a ECA e a precipitação mostra déficit hídrico na ordem de 139,4; 218,0; 578,1; 667,2; 480,8, 43,2 e 290,8 mm, para os períodos de set a dez/99; jan a dez/00; jan a dez/01; jan a dez/02; jan a dez/03; jan a dez/04 e jan a set/05, respectivamente. Este déficit, por outro lado, é função da ausência ou dos baixos valores precipitados entre os meses de junho a setembro e de uma elevada demanda d'água

B.

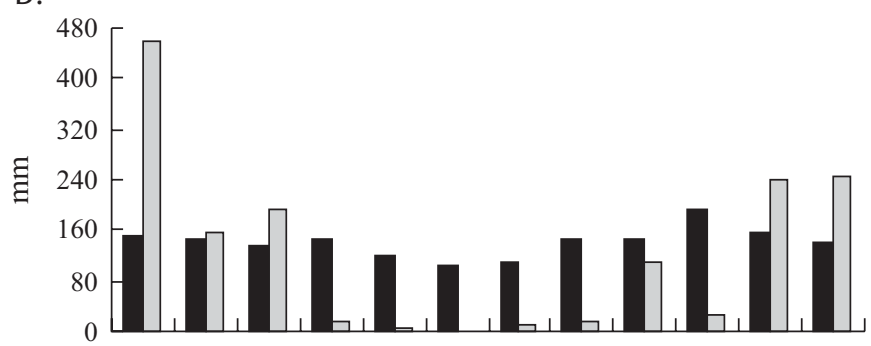

D.

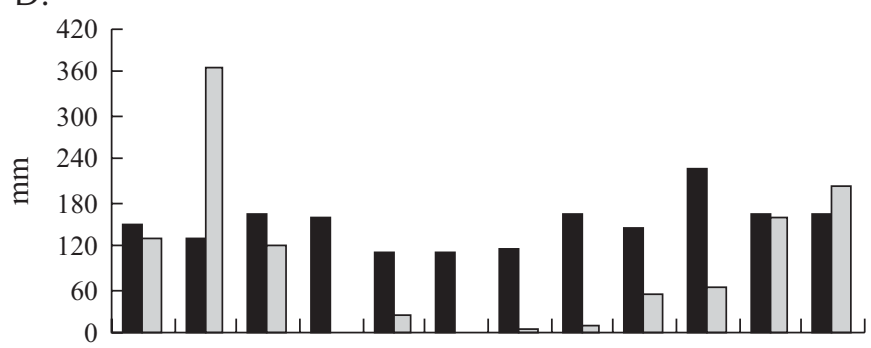

F.

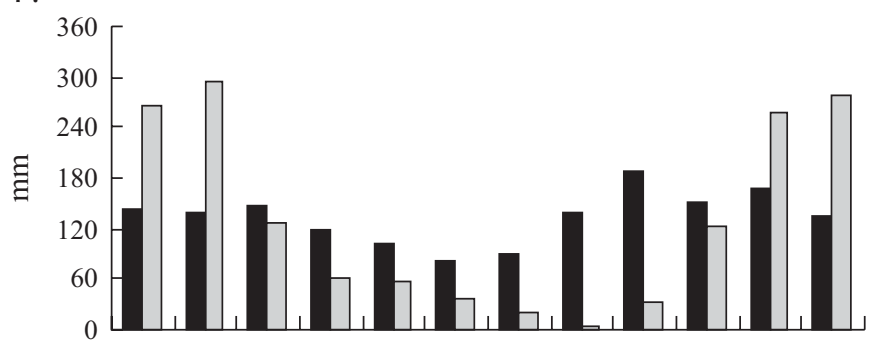

$\mathrm{H}$.

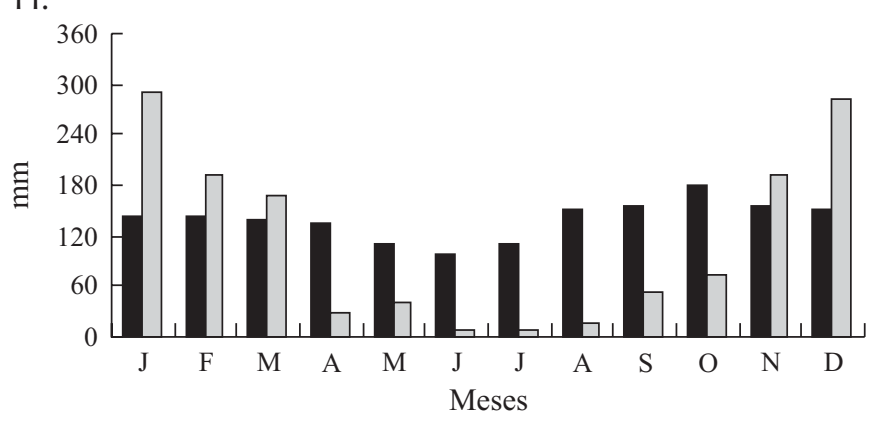

ECA média $\square$ P média

Figura 1. Totais mensais (mm) para evaporação do tanque classe "A" (ECA) e precipitação (P): A) 1999, B) 2000, C) 2001, D) 2002, E) 2003, F) 2004, G) 2005 e H) média no período de 1999 a 2005. Dados fornecidos pela Estação Climatológica da UFLA - Lavras, MG 
pela atmosfera, o que pode ser constatado através dos valores da ECA, superiores a 5,0 $\mathrm{mm} \mathrm{dia}^{-1}$ (Figura 1). Segundo Santinato et al. (1996), um déficit hídrico de $150 \mathrm{~mm}$ é capaz de comprometer a produção do cafeeiro. No período de estudo (set/1999 a set/2005), em apenas dois anos (1999 e 2004) o déficit hídrico ficou abaixo dos $150 \mathrm{~mm}$; pode-se, então, com bases nesses dados, justificar a irrigação do cafeeiro para a região de Lavras, mesmo apresentando precipitação média anual de ordem de 1529,7 mm (Normais climatológicas, 1992).

As lâminas aplicadas aos diferentes tratamentos durante o período em que o estudo foi desenvolvido, podem ser vistas na Figura 2; a lâmina do tratamento T1 (0\% ECA) corresponde apenas aos valores precipitados $(\mathrm{P})$, enquanto para as demais se somam a este os valores da ECA corrigidos pelos fatores 0,6 (T2); 0,8 (T3); 1,0 (T4); 1,2 (T5) e 1,4 (T6). Em termos médios mensais, o tratamento T1 recebeu, ao longo dos 73 meses de avaliações (set/99 a set/ 05) uma precipitação de $113,8 \mathrm{~mm}$; no mesmo período, a ECA média foi de $142,9 \mathrm{~mm}$, caracterizando um déficit mensal de 29,1 mm, anual de 394,6 mm e, ao final do experimento, de 2126,5 $\mathrm{mm}$.

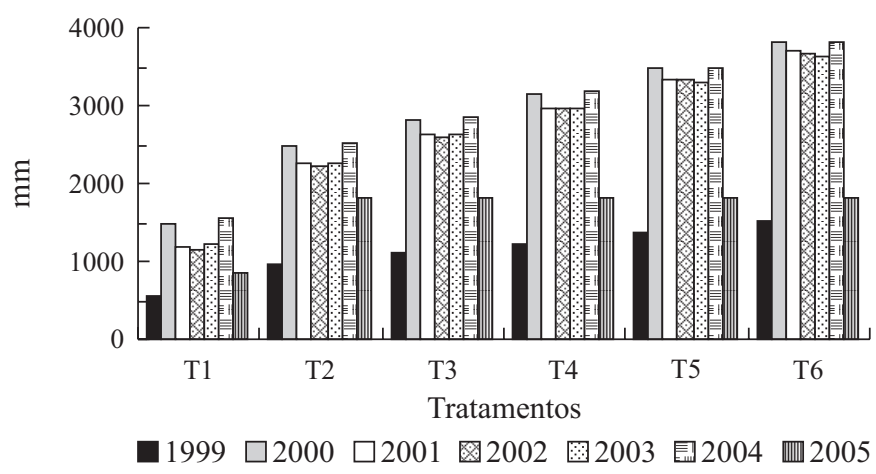

Figura 2. Lâminas anuais aplicadas aos diferentes tratamentos, acrescidas das precipitações anuais para a região de Lavras, MG, no período de ago/ 1999 a set/2005. Os valores de precipitações anuais foram fornecidos pela Estação Climatológica da UFLA - Lavras, MG

Quando da mesma análise para o tratamento T2 (60\% ECA), menor lâmina, constata-se que foi aplicada uma lâmina mensal de 209,1 mm, superior em 66,2 mm à ECA média mensal ultrapassando, portanto, o total evapotranspirado em 794,0 mm no decorrer de um ano, o que equivale à proporção de 0,52\% das precipitações anuais para Lavras. A mesma comparação para os demais tratamentos (T3, T4, T5 e T6), permite constatar que as lâminas médias mensais aplicadas superaram a ECA mensal em 96,0; 125,9; 155,7 e 188,6 mm, respectivamente; anualmente, esses valores chegam a 1152,2; 1510,56; 1868,8 e 2227,1 mm, o que corresponde a 0,$75 ; 0,98 ; 1,22$ e 1,46\% da precipitação média anual para a região de Lavras, MG.

\section{Crescimento vegetativo}

No decorrer do período estudado (set/99 a dez/04) avaliaram-se, vinte e duas vezes, os parâmetros vegetativos de crescimento das plantas e, em nove avaliações, detectou-se diferença estatística significativa a 5\% de probabilidade. Em março de 2002 a média para o parâmetro número de nós do ramo plagiotrópico para os tratamentos T1, T4, T5 e T6, variou entre 27,6 a 28,6 diferindo dos tratamentos T2 e T3 os quais apresentaram médias superiores a 30,1 nós por ramo; no mesmo ano, para a avaliação realizada em junho, apenas o diâmetro de caule se diferenciou estatisticamente. Os tratamentos T1, T3 e T4 apresentaram diâmetro de caule inferior a 49,5 mm; já T2, T5 e T6 superaram os 51 mm. Em março de 2003 o parâmetro altura de planta foi o único a ter efeito significativo com o teste de média mostrando diferença entre o T1 (testemunha, não irrigado) e os tratamentos irrigados; nesta ocasião, a altura média das plantas testemunhas era de $151,9 \mathrm{~cm}$ enquanto a altura das irrigadas ultrapassava os $170 \mathrm{~cm}$ com destaque para o T2, que apresentou altura média de plantas da ordem de 181,3 cm; em setembro deste mesmo ano o parâmetro altura de plantas voltou a apresentar diferença estatística significativa entre as plantas não irrigadas e irrigadas; neste período, as plantas testemunha cresceram apenas $6,8 \mathrm{~cm}$, pois indicaram altura média de 158,7 cm; já as plantas irrigadas, especificamente o T2, cresceu $8,4 \mathrm{~cm}$, tendo altura média igual a 189,7 cm, enquanto na avaliação de dezembro de 2003 a altura de plantas continuou a ser o único parâmetro a apresentar diferença estatística significativa e, nesta ocasião, as plantas não irrigadas atingiram altura média de $162 \mathrm{~cm}$, enquanto os demais apresentaram altura entre 180 a $193 \mathrm{~cm}$, com destaque novamente para o T2 entre os tratamentos irrigados. Na avaliação de março de 2004 dois parâmetros apresentaram diferença estatística significativa entre as plantas irrigadas e não irrigadas; o número médio de ramos plagiotrópicos nas plantas testemunhas foi de 105,6 e, nas irrigadas, superior a 116 ramos, com destaque para o T2 que apresentava média de 123,6 ramos por planta. A altura de plantas se manteve diferente estatisticamente entre plantas irrigadas e não irrigadas destacando-se novamente o T2, apresentando altura de 200,0 cm. Em junho de 2004, três parâmetros indicaram diferença estatística significativa sendo o número de internódios dos ramos plagiotrópicos e o número de ramos plagiotrópicos entre plantas não irrigadas e irrigadas; entre as plantas irrigadas e mesmo não havendo diferença estatística, o T2 novamente se destacou apresentando médias de 40,7 internódios por ramo plagiotrópico e 126,1 ramos plagiotrópicos por planta; nesta avaliação, a altura das plantas testemunhas e o T3 foram estatisticamente iguais, 173,7 cm e 187,0 cm mas diferiram das demais (T2, T4, T5 e T6), as quais variaram entre 199,6 a 204,1 cm de altura. Em setembro de 2004 o número de ramos plagiotrópicos voltou a apresentar diferença estatística significativa entre plantas irrigadas e não irrigadas, com as primeiras obtendo média de 111,0 ramos por planta enquanto o número de ramos plagiotrópicos por planta, do segundo grupo variou entre 120,1 a 128,6 ramos, sobressaindo-se entre os tratamentos irrigados o T2. Na última avaliação de crescimento vegetativo, em dezembro de 2004, apenas a variável número de ramos plagiotrópicos apresentou diferença estatística significativa, havendo separação do grupo irrigado com a testemunha (Tabela 1). Novamente as plantas que recebem lâmina de 60\% da ECA se destacaram entre as irrigadas. 
Tabela 1. Comparação de médias das lâminas aplicadas para altura de planta (A.p.), diâmetro de caule (D.c.), número de ramos plagiotrópicos ( $N^{0}$ R. P.), comprimento de ramos plagiotrópicos (C. R. P.) e número de internódios dos ramos plagiotrópicos ( $N^{\circ}$ I.R. P.), avaliados em dezembro de 2004. UFLA - Lavras, MG

\begin{tabular}{|c|c|c|c|c|c|}
\hline \multirow{2}{*}{$\begin{array}{l}\text { Lâminas } \\
\text { (\% ECA) }\end{array}$} & \multicolumn{5}{|c|}{ Parâmetros avaliados } \\
\hline & A.p. (cm) & D.c (mm) & $N^{0}$ R. P. & C. R.P. & $\mathrm{N}^{0}$ I. R P. \\
\hline 0 & $182,54 a$ & $62,96 \mathrm{a}$ & $116,82 \mathrm{a}$ & $84,93 a$ & $35,99 a$ \\
\hline 60 & $210,36 a$ & $68,39 a$ & $135,62 a$ & $90,68 a$ & $35,62 a$ \\
\hline 80 & $195,41 a$ & $66,42 \mathrm{a}$ & $126,85 \mathrm{a} 1 \mathrm{a}$ & $81,17 \mathrm{a}$ & $35,69 a$ \\
\hline 100 & $207,36 a$ & $66,24 a$ & $130,83 \mathrm{a} 1 \mathrm{a}$ & $84,65 a$ & $35,84 a$ \\
\hline 120 & $210,26 a$ & $68,28 a$ & $129,58 \mathrm{a} 1 \mathrm{a}$ & $90,75 a$ & $38,14 a$ \\
\hline 140 & $205,29 a$ & $70,58 a$ & $129,42 \mathrm{a} 1 \mathrm{a}$ & $91,37 \mathrm{a}$ & $37,94 a$ \\
\hline
\end{tabular}

Valores seguidos de mesma letra e número na coluna não se diferenciam estatisticamente $(p<0,05)$

Mesmo não tendo diferença estatística significativa entre os tratamentos irrigados, percebeu-se que a lâmina de $60 \%$ da ECA (T2), apresentou os melhores resultados em relação aos parâmetros avaliados; detectou-se, no campo, de forma visual, ligeira superioridade no crescimento e desenvolvimento dessas plantas quando comparadas com as demais. Em termos percentuais, quando se comparam as plantas do tratamento T2 com as do tratamento T1, observa-se que as primeiras são $15,2 \%$ mais altas, apresentam $16,1 \%$ a mais de ramos plagiotrópicos, e são 6,8\% maiores. Os parâmetros e avaliações não mencionados não foram ou não apresentaram significância a nível de 5\% de probabilidade.

A Figura 3 mostra o comportamento dos parâmetros diâmetro de caule e altura de planta nas vinte e duas avaliações, para as plantas não irrigadas (T1) e irrigadas com 60\% da ECA (T2). Nota-se que início das avaliações, praticamente, não houve diferença entre os tratamentos, o que pode ser visto pela sobreposição das curvas até a quarta avaliação,

$$
\text { A. }
$$

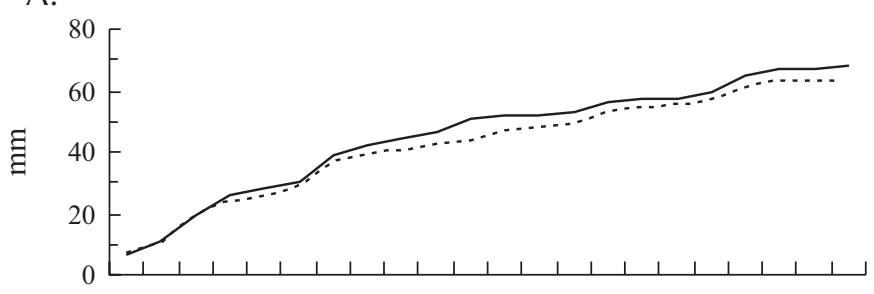

B.

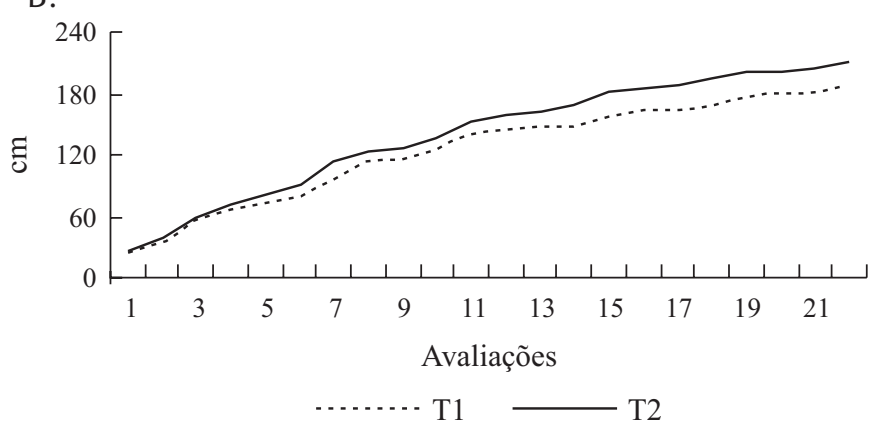

Figura 3. Variação dos parâmetros: A) diâmetro de caule (mm) e B) altura de planta $(\mathrm{cm})$ nas vinte e duas avaliações (ago./1999 a dez./2004), para as plantas não irrigadas (T1) e irrigadas com $60 \%$ da ECA (T2). UFLA Lavras, MG quando então, se diferenciaram, mas mantiveram comportamento semelhante ao longo do período avaliado.

Com relação às épocas do ano, percebe-se que no período seco (março a outubro), a taxa de crescimento das plantas irrigadas tende a aumentar, o que pode ser facilmente visto pela inclinação dos segmentos de retas neste período, enquanto para as plantas não irrigadas esta tendência é mínima; para o período chuvoso, a tendência de crescimento mostrada na Figura 3 é similar para ambos; para todos os parâmetros avaliados e lâminas aplicadas, verificou-se a mesma tendência de comportamento.

\section{Produtividade e produção acumulada}

O resumo da análise de variância com a soma de quadrados (SQ), para as produtividades anuais, em sc de $60 \mathrm{~kg} \mathrm{ha}^{-1}$, obtida pela lavoura nas cinco safras para as diferentes lâminas de irrigação, acha-se na Tabela 2. Observa-se que as lâminas de irrigação não se diferenciaram estatisticamente em nenhuma das safras estudadas. Os coeficientes de variação apresentados por esta tabela são indicativos de que ocorreu alta variabilidade na produtividade dos tratamentos em uma mesma safra (comparação entre colunas), com os maiores valores deste coeficiente intercalados entre os menores.

Tabela 2. Resumo da análise de variância com a soma de quadrados (SQ), para a produtividade (café de pano), das safras 00/01, 01/02, 02/03, 03/04 e 04/05 em sacas de 60 kg (P. Ac.) para as lâminas aplicadas em função da ECA. UFLA - Lavras, MG

\begin{tabular}{|c|c|c|c|c|c|c|}
\hline \multirow{2}{*}{ F.V. } & \multirow{2}{*}{ GL } & \multicolumn{5}{|c|}{ Soma de Quadrados } \\
\hline & & $00 / 01$ & $01 / 02$ & $02 / 03$ & $03 / 04$ & $04 / 05$ \\
\hline Lâmina & 5 & $1931^{\text {ns }}$ & $3101^{\text {ns }}$ & $3724^{\text {ns }}$ & $1473^{\text {ns }}$ & $315^{\mathrm{ns}}$ \\
\hline Bloco & 2 & $871^{\text {ns }}$ & $2^{\mathrm{ns}}$ & $245^{\text {ns }}$ & $308^{\text {ns }}$ & $33^{\text {ns }}$ \\
\hline Erro & 10 & 2554 & 2365 & 2700 & 5797 & 1388 \\
\hline Total & 17 & 5356 & 5468 & 6669 & 7577 & 1736 \\
\hline \multicolumn{2}{|c|}{ CV (\%) } & 40,1 & 52,3 & 33,1 & 62,5 & 26,0 \\
\hline
\end{tabular}

ns Não significativo

Este fato pode estar associado à bianualidade da produção, o que permite inferir que a irrigação não foi capaz de evitar essa característica da lavoura, ficando melhor evidenciado pela Figura 4, que mostra queda na produção para todos os tratamentos irrigados nas segunda e quarta safras e maiores produtividades nas primeira e terceira safras.

Observando-se a representação gráfica da Figura 4 para o tratamento T1 constata-se que a produtividade da primeira e terceira safras está próxima de $20 \mathrm{sc} \mathrm{ha}^{-1} \mathrm{ano}^{-1}$ e quase zero para a segunda safra; este comportamento evidencia a bianualidade da lavoura e mostra que a irrigação pode não evitá-la mas ajuda a reduzi-la, pois a queda de produtividade nos tratamentos irrigados não foi tão acentuada quanto na testemunha.

Outra possível explicação para a acentuada redução de produtividade do $\mathrm{T} 1$, pode estar relacionada ao forte déficit hídrico ocorrido nos meses de abril a junho do ano anterior (Figura 1), o que comprometeu a produtividade desta safra. O déficit hídrico para os anos de 2001 e 2002 foi da ordem de 578,1 e $667,2 \mathrm{~mm}$, respectivamente. 
Para a quarta safra a produtividade do tratamento testemunha alcançou os patamares dos tratamentos irrigados devido, provavelmente, à redução da produtividade em função da bianualidade para os tratamentos irrigados e, também, a um possível esgotamento fisiológico dessas plantas, pois apresentaram produtividades elevadas desde a primeira safra, quando ainda estavam em formação. Outro fato que pode ter colaborado para a elevada produtividade das plantas não irrigadas na quarta safra, é a não ocorrência de déficit hídrico, como nos anos anteriores, igualando-se este tratamento aos irrigados.

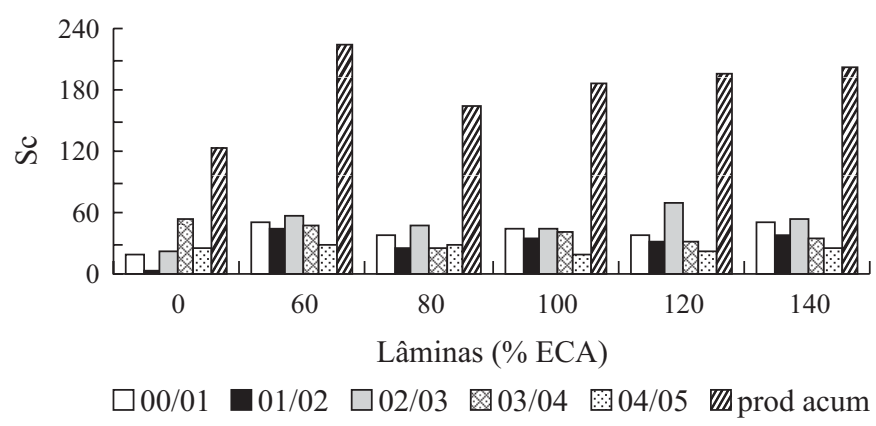

Figura 4. Produtividade em sc de $60 \mathrm{~kg} \mathrm{ha}^{-1}$ para as lâminas aplicadas em função da ECA, para as safras 00/01, 01/02, 02/03, 03/04, 04/05 e produção acumulada nas cinco primeiras safras. UFLA - Lavras, MG

A produtividade do tratamento T2 foi superada apenas pelo T6 na primeira safra; no decorrer do experimento e mesmo não havendo diferenças estatísticas significativas entre as plantas irrigadas, as plantas do tratamento T2 apresentaram melhores índices de desenvolvimento vegetativo (Tabela 1), o que contribuiu para que estas apresentassem maiores produtividades. Observando-se as safras acumuladas (Figura 4 e Tabela 3), tem se que este fato fica evidente, pois o tratamento T2, é o que soma a maior produção acumulada entre todos os tratamentos irrigados ao final de cinco safras, 225,6 sc e produtividade média de $45,1 \mathrm{sc} \mathrm{ha}^{-1} \mathrm{ano}^{-1}$, seguido do T6, com 201,2 sc ha-1 ano $^{-1}$ e produtividade média de 40,2 sc ha-1 ano $^{-1}$.

O T1 teve a menor produção acumulada dentre os tratamentos avaliados, estando próxima de 120 sc ao longo do período analisado; já na segunda safra (Tabela 3), acumulan-

Tabela 3. Resultado do teste de comparação de médias, feito pelo método de Tukey, para as safras acumuladas para as lâminas aplicadas em função da ECA. UFLA - Lavras, MG

\begin{tabular}{cllcl}
\hline Lâminas & \multicolumn{4}{c}{ Safras acumuladas } \\
\cline { 2 - 5 }$(\% \mathrm{ECA})$ & $\mathbf{2}$ & $\mathbf{3}$ & $\mathbf{4}$ & $\mathbf{5}$ \\
\hline 0 & $21,68 \mathrm{a} 1$ & $44,42 \mathrm{a} 1$ & $95,36 \mathrm{a} 1$ & $119,89 \mathrm{a} 1$ \\
60 & $92,15 \mathrm{a} 2$ & $147,96 \mathrm{a} 2$ & $195,93 \mathrm{a} 1$ & $225,61 \mathrm{a} 1 \mathrm{a} 2$ \\
80 & $62,82 \mathrm{a} 1 \mathrm{a} 2$ & $111,27 \mathrm{a} 1 \mathrm{a} 2$ & $136,54 \mathrm{a} 1$ & $164,35 \mathrm{a} 1 \mathrm{a} 2$ \\
100 & $80,45 \mathrm{a} 2$ & $126,04 \mathrm{a} 2$ & $166,97 \mathrm{a} 1$ & $186,97 \mathrm{a} 1 \mathrm{a} 2$ \\
120 & $71,15 \mathrm{a} 1 \mathrm{a} 2$ & $141,61 \mathrm{a} 2$ & $173,15 \mathrm{a} 1$ & $195,61 \mathrm{a} 1 \mathrm{a} 2$ \\
140 & $87,26 \mathrm{a} 2$ & $142,20 \mathrm{a} 2$ & $176,60 \mathrm{a} 1$ & $208,71 \mathrm{a} 2$ \\
\hline
\end{tabular}

Números seguidos do mesmo índice alfanumérico nas colunas não se diferem estatisticamente entre si. 2 = somatório das duas primeiras safras $(00 / 01$ e $01 / 02) ; 3=$ somatório das três primeiras safras $(00 / 01,01 / 02$ e 02/03); 4 = somatório das quatro primeiras safras (00/01, 01/02, 02/03 e 03/04) e

$5=$ somatório das cinco primeiras safras $(00 / 01,01 / 02,02 / 03,03 / 04$ e 04/05) do a produção, os tratamentos irrigados se diferenciaram do não irrigado, com a lâmina de $60 \%$ da ECA, destacando-se entre os irrigados, situação esta que permaneceu inalterada para a próxima safra (02/03), quando foi avaliado o acumulado das três primeiras safras; no acumulado das quatro primeiras safras os tratamentos se igualaram estatisticamente, devido à elevada produtividade obtida pelas plantas não irrigadas nesta safra (03/04), o que pode ser facilmente percebido na Figura 4, em função de fatores anteriormente comentados.

A última safra analisada (04/05) se comportou como as três primeiras, ou seja, a produção acumulada dos tratamentos irrigados voltou a se diferenciar do não irrigado, destacando-se a lâmina de $60 \%$ da ECA. Analisando-se as 5 safras percebe-se, na Tabela 3, diferença estatisticamente significativa (5\%) entre os tratamentos irrigados e a testemunha (não irrigada).

\section{CONCLUSÕES}

1. A irrigação, mesmo em regiões consideradas aptas ao cultivo do café, como Lavras, Sul de Minas Gerais, promoveu acréscimo significativo na produtividade do cafeeiro Coffea arabica L. cv. Rubi.

2. O tratamento testemunha (sem irrigação) produziu, em média, 24,6 sc ha-1 ano ${ }^{-1}$ enquanto o irrigado, com $60 \%$ da ECA (T2), obteve produtividade média de 45,12 sc ha-1 $\mathrm{ano}^{-1}$.

3. Dentre as lâminas aplicadas a que apresentou os melhores resultados fisiológicos e de produtividade, foi a de $60 \%$ da ECA.

4. Por razões técnicas e econômicas, esta lâmina (60\% da ECA), deve ser adotada pelos cafeicultores da região de Lavras para irrigar a lavoura cafeeira, quando se utiliza pivô central para suprir a demanda hídrica das plantas.

5. As plantas irrigadas apresentaram maior desenvolvimento vegetativo no período seco, março a outubro.

\section{LITERATURA CITADA}

Antunes, R. C. B.; Mantovani, E. C.; Soares, A. R.; Rena, A. B; Bonomo, R. Área de observação e pesquisa em cafeicultura irrigada na região das vertentes de Minas Gerais - resultados de 1998/2000. In: Simpósio de Pesquisa dos Cafés do Brasil, 1, 2000, Poços de Caldas. Resumos... Brasília: Embrapa Café e Minasplan, v.2, p.823-826, 2000.

Camargo, A. P. de. Balanço hídrico, florescimento e necessidade de água para o cafeeiro. In: Simpósio Sobre o Manejo de Água na Agricultura, Campinas, 1987. Campinas: Fundação Cargill, 1987, p.53-90.

Castro Neto, P. Veranico: um problema de seca no período chuvoso. Informe Agropecuário, Belo Horizonte, v.12, n.138, p.59-62, 1986.

Faria, M. A. de; Vilela, W. M. da C.; Silva, M. de L. O.; Guimarães, P. T. G.; Silva, E. L. da; Oliveira, L. A. L. da. Influência das lâminas de irrigação e da fertirrigação na produtividade do cafeeiro (Coffea arábica L.) 2ª colheita. In: Simpósio Brasileiro de Pesquisa em Cafeicultura Irrigada, 4, 2001, Araguari. Resumos... Uberlândia: UFU/DEAGRO, 2001. p.11-14. 
Matielo, J. B.; Miguel, A. E.; Vieira, E.; Aranha, E. Novas observações sobre os efeitos hídricos no pegamento da florada de cafeeiros. In: Congresso Brasileiro de Pesquisas Cafeeiras, 21, Caxambu. Resumos... Caxambu: Ministério da Agricultura, Pecuária e Abastecimento e SARC/PROCAFÉ. 1995, p.60.

Normais Climatológicas - Departamento Nacional de Meteorologia. Rio de Janeiro. (1961-1990). 1992. 84p.

Santinato, R.; Fernandes, A. L. T.; Fernandes, D. R. Irrigação na cultura do café. Campinas: Arbore, 1996. 146p.
Scalco, M. S.; Morais, A. R. de; Colombo, A.; Carvalho, C. H. M. de; Faria, M. A. de; Melo, L. Q. de; Silva, E. L. da. Influência de diferentes critérios de irrigação e densidade de plantio sobre o crescimento inicial do cafeeiro. In: Simpósio Brasileiro de Pesquisa em Cafeicultura Irrigada, 5, 2002, Araguari. Resumos... Uberlândia: UFU/DEAGRO, 2002. p.150-155.

Sorice, L. S. D. Irrigação e fertirrigação de cafeeiros em produção. Lavras: UFLA, 1999. 59p. Dissertação Mestrado 